extends the range of water/cement ratios towards lower limits than were previously practicable, with the results that strength and density can be improved, shrinkage and creep are reduced, and the bond with reinforcing steel is increased.

In 1932, research on the stresses set up during the driving of reinforced concrete piles was commenced at the Building Research Station and was carried on in collaboration with the Federation of Civil Engineering Contractors. It was initiated as a direct result of the difficulties experienced under certain conditions of hard driving, where it was found impossible to comply with the specification and at the same time to avoid serious damage to the pile. This is one of the investigations in which the Civil Engineers' Committee is now co-operating and, as it happens, the report of the research work carried out has also recently been issued ${ }^{2}$. In and around London there are many building sites where the ground consists of alluvial or made-up soil of very low bearing power for a depth of 10-30 ft. Below this is a stratum of hard compact gravel the thickness of which on any one site may vary from a foot or two to so much as 20 feet. Under the gravel, soft earth of low-bearing power is again found and at a still greater depth the hard compact clay is reached. The uncertainty of the gravel stratum as a foundation for important structures has made it advisable to found on the hard clay. It is in the penetration of the gravel that the difficulties referred to have been experienced, and excavation of driven piles has revealed unsuspected damage underground. Uncertainty was, in consequence, felt as to the condition of piles driven on such sites. The current theory assumes uniform stress distribution through the pile; but, as the velocity of stress propagation in a reinforced-concrete pile is approximately $12,000 \mathrm{ft}$. per second, research was necessary. This involved an examination of the nature and magnitude of the stresses induced in piles by impact, a study of the effect upon impact resistance of the design and methods of manufacture of the pile, and the development of means of indicating dangerous conditions during driving.

In addition to a number of facts of the highest practical importance which have emerged from the research, as to both the conditions which arise and the best methods of driving, a mathematical theory is outlined which is shown to conform to the results of the experimental investigation in all its main conclusions and to be applicable to estimate the stress at any point under known conditions. An expression is given for the Young's modulus of an equivalent homogeneous pile; but, as the mathematical expressions for the stresses are too complicated for practical use, the results have been given in the form of charts showing the maximum compressive stresses at the head and foot for different weights of hammer, stiffnesses of cushion, etc. Further research is suggested, and it is obvious that one of the chief sources of uncertainty and trouble is the unsatisfactory nature of existing methods of cushioning the blow. A head cushion of constant properties and capable of ensuring a uniform distribution of stress over the pile head would not only prevent the majority of head failures but also would enable data to be collected on bearing capacity under controlled head conditions. Of the packings in common use which were tested in the special impact machine, sackcloth has so far exhibited the best characteristics.

\footnotetext{
1 The Institution of Civil Engineers. Report of the Research Committee for the years $1935-36$ and 1936-37. Published by the Institution, Great George Street, S.W.1.

2 "An Investigation of the Stresses in Reinforced Concrete Plles during Driving". Building Research Technical Paper No. 20 (Department of Scientific and Industrial Research). (London: H.M. Stationery Office, 1938.) 38. net.
}

\title{
Training and Research in Electrical Engineering
}

$\mathrm{D}$ R. A. P. M. Fleming, in his inaugural address to the Institution of Electrical Engineers on October 20, discussed the progress made in the methods of selecting the personnel required for the electrical engineering industry and the methods employed to develop scientific discoveries. In former days, ideas were conceived and developed by the individual effort of men of genius; to-day, in the universities and great scientific laboratories, teams of scientific workers are at work, extending the boundaries of knowledge, out of which possible applications in industry may emerge. The great manufacturing organizations find it necessary to be continually increasing their technically trained staff and to engage men of wide scientific attainments so as to apply the knowledge that practical research yields.

Many of the new discoveries affecting our industry arise from the work of the physicist. The field in which the physicist now works has developed in such a manner that, compared with fifteen years ago, he often needs for his researches plant of great engineer. ing magnitude-plant which has to yield hundreds of thousands of kilowatts or many millions of volts. On this account, as well as for other reasons, it is probable that the great manufacturing organizations will undertake more and more fundamental research.

A pleasing feature during the last ten years has been the tendency towards co-operative research whereby problems of common interest to a large number of different organizations are pooled. This avoids overlapping of effort and has enabled the smaller concerns to profit equally with the large ones, for the knowledge thus revealed is available to all on the same common basis as a raw-material supply. A great deal of the responsibility for continued technical development falls on the manufacturer. The manufacturing branch of the electrical industry now employs 70 per cent of all the workers engaged in electrical applications.

There are three principal educational levels of entry into the electrical industry. In the lowest of these are those youths who are recruited at ages between fourteen and sixteen years from the elementary, central, junior technical and junior secondary schools ; the intermediate level comprises those of sixteen to eighteen years of age, who have reached matriculation or higher school certificate standard in secondary schools, whilst in the highest level are those who 
enter as graduates from the universities and large technical colleges.

The electrical profession is a democratic one, in that no matter what the educational level of the entrant is, he can, if he has the requisite ability and ambition, climb to the highest ranks. The importance of attracting the very best recruits from each level and of encouraging, and affording facilities for, the upward mobility of the individual according to his aptitude and capability, cannot be over-estimated.

The question of the selection of a recruit for a particular post is most important. Dr. Fleming is of the opinion that for most types of industrial employment the best results are obtained when methods of self-selection are employed, and the entrant is given an opportunity after he has had some manufacturing experience under sympathetic guidance, of deciding for himself the branch of works to which he is best suited. An increasing number of youths entering from the lowest educational level secure promotion through following a course of technical study leading to national certificates. There is now an increasing tendency on the part of employers to permit their apprentices to attend equivalent part-time day courses in the local technical institutions.

This democratic tendency is in sharp contrast to the system in operation in Germany where, for the most part, the upper level attainable even by an ambitious youth is dictated by his starting level. This restricting feature must react on the enthusiasm of one forced to resign himself to a predetermined status with little if any prospect of further advancement. The U.S.S.R. plan has certain political limitations, but it endeavours to select, educate and train its entrants to industry, solely on the basis of merit, with a considerable amount of success.

\section{University Events}

Leens.-Dr. P. I. Sutherland has been elected to the chair of forensic medicine in succession to the late Prof. Maxwell Telling. Prof. Sutherland, a graduate of the University of Glasgow, has held an appoint. ment in the University as lecturer in the pathology of industrial diseases since 1920. He has been since 1910 pathologist to the West Riding County Council, a post which he will continue to hold.

LoNDON.-Dr. Harry Jones has been appointed as from October 1 to the University readership in mathematics tenable at the Imperial College--Royal College of Science. During 1933-37 he was lecturer in theoretical physics in the University of Bristol, and since October 1937 he has been attached to the Royal Society Mond Laboratory in Cambridge.

Mr. F. W. Paish has been appointed as from October 1, 1938, to the Sir Ernest Cassel readership in business finance tenable at the London School of Economics. Since 1932 he has been one of the Sir Ernest Cassel lecturers in commerce at the School and also secretary of the London and Cambridge Economic Service.

The following titles have been conferred in respect of posts held at the institutions indicated : professor of Near Eastern archæology on Mr. Sidney Smith (Institute of Archæology) ; reader in electrical engineering on Dr. H. E. M. Barlow (University College).

\section{Science News a Century Ago}

\section{The Ashmolean Society}

AT a meeting of the Ashmolean Society, Oxford, on October 29, 1838, Prof. Baden Powell read a paper entitled "On Refractive Indices". The object of this communication was to state the results of a series of observations, in which the author had been engaged during the summer, in extension and verification of his former researches. Besides the general object of more accurate determination of refractive indices for definite rays in several important media, he had in view the settlement of some points on which questions had been raised, and in some preliminary remarks, he adverted especially to certain objections raised by Sir David Brewster at the New. castle meeting of the British Association. At Newcastle, Powell had read a paper entitled "On Some Points connected with the Theory of Light" while Brewster had read another entitled "On a New Kind of Polarity in Homogeneous Light". In the discussion on these papers there was a marked difference of opinion, and this found expression also in the pages of the Athenceum after the reading of Powell's paper to the Ashmolean Society.

\section{The Zoological Society}

AT a meeting of the Zoological Society on November 1,1838 , the annual report, which was read, stated that the receipts for the year up to October 31 amounted to $£ 13,230$ and the expenditure to $£ 10,997$, leaving a balance of $£ 2,232$. The council had determined upon an alteration in the mode of introduction to the gardens on Sundays. Each fellow was to have a ticket for his own personal use and two checks for the admission of friends.

\section{Henry's Electrical Researches}

ONE of the most important memoirs of Prof. Joseph Henry, of Princeton College, was that "On Electro-dynamic Induction" read to the American Philosophical Society on November 2, 1838, in which he gave the results of his extension of the purely electrical part of "Faraday's Admirable Discovery". In his experiments, Henry had employed "five different sized annular spools of fine wire (about one-fiftieth of an inch thick) varying from one-fifth of a mile to nearly a mile in length (which might be called 'intensity' helices); and six flat spiral coils of copper ribbon varying from three-quarters of an inch to one inch and a half in width, and from 60 to 93 feet in length (which might be ealled 'quantity' coils)". These he combined in various ways. By the alternations of the ribbon and wire coils, the fact was established "that an intensity current can induce one of quantity, and by the preceding experiments the converse has also been shown that a quantity current can induce one of intensity; a result which has had an important bearing on the subsequent development of the electro-magnetic induction coil" (W. B. Taylor's discourse on the scientific work of Joseph Henry). In his experiments, Henry used various batteries, one being a cylindrical battery of one and three-quarters square feet of zinc surface, another a Cruickshanks battery of 60 elements 4 inches square and another Dr. Hare's battery, 32 one-gallon jars. The investigations were fully dealt with by the French physicist, Antoine C. Becquerel, in vol. 5 of his "Traité expérimental de l'Électricité et du Magnétisme". 